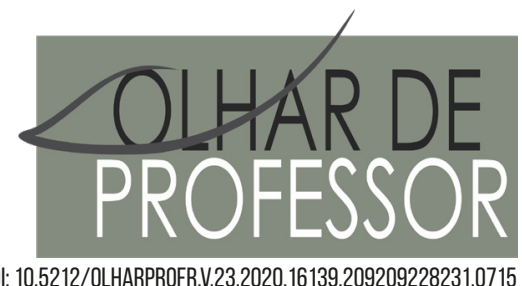

DOI: 10.5212/OLHARPROFR.V.23.2020.16139.209209228231.0715

\title{
IX DIMA ON-LINE: UMA EXPERIÊNCIA EXITOSA EM PERÍODO DE PANDEMIA
}

\author{
IX DIMA ON-LINE: A SUCCESSFUL EXPERIENCE IN A PANDEMIC PERIOD
}

\section{DIMA EN LIINEA: UNA EXPERIENCIA DE ÉXITO EN UN PERÍODO PANDÉMICO}

\author{
ELIZIETE NASCIMENTO DE MENEZES ${ }^{*}$ \\ FRANCISCO ARNALDO LOPES BEZERRA* \\ MARIA JOSÉ COSTA DOS SANTOS ${ }^{\text {*** }}$
}

\begin{abstract}
Resumo: Este relato tem o objetivo de apresentar uma experiência de realização do evento Diálogos da Matemática com a Pedagogia (DIMA) em período de isolamento social, em decorrência de uma pandemia mundial ocasionada pela COVID-19. Inicialmente, apresentamos o que é o DIMA; em seguida, relatamos a experiência de realizar o webinário IX DIMA em 2020, por meio de um panorama de como se deu o evento desde o planejamento, a organização e a execução, de modo a atender às orientações da Organização Mundial de Saúde de isolamento social. Por fim, fazemos algumas considerações, com destaque para os pontos positivos da realização do DIMA on-line e possibilidades com o uso das tecnologias. Para encerrar nossa discussão, refletimos sobre o papel da Universidade e problematizamos sua postura diante do cenário da pandemia.
\end{abstract}

Palavras-chave: Matemática. Pedagogia. Pandemia. Webinário.

\begin{abstract}
This report aims to present an experience of conducting the event Dialogues of Mathematics with Pedagogy (known by the acronym DIMA) in a period of social distancing due to a global pandemic caused by COVID-19. Initially, we present what DIMA is, then we report the experience to hold the IX DIMA webinar in 2020, through an overview of how the event took place from planning, organization and execution, in compliance with the World Health Organization guidelines for social distancing. Finally, we make some considerations highlighting positive points of the realization of DIMA on-line and possibilities with the use of technologies. To end our discussion, we reflect on the role of the University and question its posture in the face of the pandemic scenario.
\end{abstract}

Keywords: Mathematics. Pedagogy. Pandemic. Webinar.

Resumen: Este relato tiene como objetivo presentar una experiencia de realización del evento Diálogos de Matemáticas con la Pedagogía (DIMA) en período de aislamiento social, debido a una pandemia mundial causada por COVID-19. Inicialmente, presentamos qué es DIMA; en seguida, relatamos la experiencia de realizar el

\footnotetext{
* Mestra em Educação pela Universidade Federal do Ceará. Professora da Prefeitura Municipal de Fortaleza. Membro do grupo de pesquisas Tecendo Redes Cognitivas de Aprendizagem G-Tercoa/CNPq, da Universidade Federal do Ceará (UFC). ORCID: https://orcid.org/0000-0002-6845-2324. E-mail: eliziete30@gmail.com

${ }^{* * *}$ Mestre em Educação Brasileira pelo Programa de Pós-Graduação da Faculdade de Educação da Universidade Federal do Ceará (FACED/UFC). Membro do grupo de pesquisa G-Tercoa. Pesquisa atualmente os seguintes temas: Educação. Pedagogia. Ensino de Matemática. ORCID: https://orcid.org/0000-0002-3560-0730. E-mail: arnaldobezerraph@gmail.com

*** Pós-Doutora em Educação pela Universidade Estadual do Rio de Janeiro (UERJ). Docente do Programa de Pós-Graduação em Educação da Universidade Federal do Ceará (PPGE/UFC). ORCID: https://orcid.org/0000-0001-9623-5549. E-mail: mazeautomatic@gmail.com.
} 
webinar IX DIMA en 2020, por medio de un panorama de cómo se llevó a cabo el evento desde la planificación, la organización y la ejecución, de modo a atender las orientaciones de la Organización Mundial de la Salud para el aislamiento social. Finalmente, hacemos algunas consideraciones, con destaque en los puntos positivos de la realización de DIMA en línea y posibilidades con el uso de las tecnologías. Para finalizar nuestra discusión, reflexionamos sobre el papel de la Universidad y cuestionamos su postura ante el escenario de la pandemia.

Palabras-clave: Matemática. Pedagogía. Pandemia. Webinar.

\section{INTRODUÇ̄̃̃o}

Este relato tem o objetivo de apresentar uma experiência de realização do evento Diálogos da Matemática com a Pedagogia (DIMA) em período de isolamento social, em decorrência de uma pandemia mundial iniciada na Ásia no final do ano de 2019, que, por sua vez, se alastrou pelo mundo e chegou ao Brasil em fevereiro ${ }^{1}$ de 2020.

A partir de então, os infectados foram espalhando-se pelos estados brasileiros com casos de COVID-19, uma doença causada pelo coronavírus SARS-CoV-2, o qual apresenta um quadro clínico que varia de infecções assintomáticas a quadros respiratórios graves, podendo levar à morte (BRASIL, 2020).

Sobre a doença, capacidade de contágio, índice de letalidade, remédios eficazes no combate ao vírus, pouco ainda se sabe, pois, somente após a disseminação pelo mundo, iniciou-se uma corrida científica para mapear seu desenvolvimento, fato que originou as descobertas iniciais, assim como as primeiras medidas de prevenção, tais como: uso de equipamentos de proteção individual (EPI), higienização das mãos, regras de etiqueta respiratória e, por fim, o isolamento social.

Esse isolamento foi causa de controvérsias entre governos e profissionais da saúde, os quais, com base em evidências científicas, defendiam de forma taxativa o afastamento social para conter o avanço da proliferação viral, enquanto que, em contrapartida, alguns governos adotavam um comportamento negacionista quanto à gravidade da doença, em favor da economia, desautorizando cientistas e médicos e defendendo a manutenção de cuidados, porém com restrições apenas para as pessoas mais vulneráveis, como idosos, portadores de doenças crônicas, entre outras comorbidades.

Dessa forma, o advento da pandemia trouxe implicações para todos os setores da sociedade, transformando a maneira de viver, de trabalhar, de relacionar-se, de estudar etc. Nesse contexto, a Organização Mundial de Saúde (OMS) instituiu o isolamento social como medida preventiva para evitar o contágio. Nesse sentido, a educação, a exemplo de outros setores, viveu um cenário de suspensão de suas atividades presenciais com o fechamento de escolas, universidades, entre outros espaços educativos sob o intuito de evitar aglomeração, conforme recomendado pela World Health Organization (WHO, 2020).

Diante desse novo normal, o estado do Ceará vivenciou um momento de posicionamento das autoridades públicas locais, por via de sucessivos Decretos por parte do Governo, como o Decreto N ${ }^{\circ}$ 33.519, de 19 de março de 2020, que intensificou medidas para o enfrentamento e a contenção da infecção (CEARÁ, 2020). Nesse contexto, a Universidade Federal do Ceará (UFC) também se posicionou perante à comunidade acadêmica com orientações para a suspensão de atividades presenciais, bem como o desenvolvimento de atividades remotas, conforme artigo $3^{\circ}$ do Provimento $\mathrm{N}^{\circ}$ 02/CONSUNI, de 16 de março de 2020, com o objetivo de minimizar os impactos no calendário acadêmico (UFC, 2020b).

Diante do cenário relatado, este ensaio trata do evento Diálogos da Matemática com a Pedagogia (DIMA) durante o período de pandemia. O texto encontra-se estruturado da seguinte forma: inicialmente, apresentamos o que é DIMA, como o evento acontece, o público a quem se destina, entre outros aspectos. Em seguida, relatamos a experiência de realizar o webinário IX DIMA, em 2020, de modo a fazer um panorama de como se deu o evento desde o seu planejamento, a organização e a execução, atendendo às orientações da OMS de isolamento social. Por fim, fazemos algumas considerações, com destaque para os pontos positivos da realização do DIMA on-line e possibilidades com o uso das tecnologias. Para

\footnotetext{
${ }^{1}$ Segundo a reportagem Secretaria de Saúde de SP monitora pessoas que estiveram com infectado por coronavírus (JORNAL NACIONAL, 2020, n.p.).
} 
encerrar nosso texto, trazemos à reflexão o papel da Universidade nesse contexto e problematizamos a sua postura diante do cenário da pandemia.

\section{OEVENTO DIMA}

O encontro DIMAé um evento presencial que acontece anualmente, promovido pelo Grupo Tecendo Redes Cognitivas de Aprendizagem (G-Tercoa), aprovado no Conselho Nacional de Desenvolvimento Científico e Tecnológico (CNPq) e ligado à Faculdade de Educação (Faced) da UFC. O evento DIMA busca potencializar a discussão a respeito da formação do professor que ensina Matemática. A relevância do evento justifica-se pela importância das reflexões suscitadas pela temática, bem como das possibilidades de aproximação entre a Pedagogia e a Matemática, trazendo para o diálogo duas áreas distintas, de modo a estabelecer relações entre ambas, aproximar saberes e reduzir abismos epistemológicos e conceituais entre elas. Tal justificativa encontra fulcro em Santos (2007), pois, de acordo com a autora:

Podemos perceber que algumas das causas do fracasso nessa disciplina [Matemática] estão intrinsecamente ligadas a má formação dos professores, e, mais ainda à ineficiência da formação dos profissionais que vão lecionar nas séries iniciais (pedagogos), pois é preciso que os professores que vão trabalhar com o curso de Pedagogia conheçam bem os conteúdos, tenham uma visão ampla e estrutural. (SANTOS, 2007, p. 32).

Dessa forma, o objetivo do evento é compartilhar diversas práticas educativas relacionadas à formação e ao ensino de Matemática, no intuito de ampliar as experiências e, também, oferecer sugestões e ideias ao público participante. De acordo com Tardif (2014, p. 247), os “[...] conhecimentos especializados devem ser adquiridos através de uma longa formação de alto nível, na maioria das vezes, de natureza universitária ou equivalente".

O evento DIMA é direcionado para alunos do curso de Pedagogia, alunos do curso de Licenciatura em Matemática, professores da Educação Básica que ensinam Matemática (pedagogos nos anos iniciais e licenciados nos anos finais do Ensino Fundamental e do Ensino Médio), professores do Ensino Superior, também profissionais da educação e interessados na temática.

A realização do DIMA configura-se como momento favorável para discutir temas voltados ao currículo, à avaliação, à importância da pesquisa, ao uso das tecnologias e à formação de professor (inicial e continuada), entre outros, de igual modo relevantes. Para fazer parte do evento, que é divulgado entre o grupo G-Tercoa, nos espaços da Universidade, nas redes sociais e site do referido grupo, é necessário realizar inscrição. O canal do G-Tercoa, bem como os perfis do grupo nas plataformas de mídias sociais, Instagram $^{3}$, Facebook ${ }^{4}$ e YouTube ${ }^{5}$, trazem todas as informações sobre o evento: a programação, as datas e os horários, a certificação $0^{6}$ a participação com apresentação de trabalhos, bem como normas e prazos para submissão.

O evento, que reúne estudantes, professores, pesquisadores e demais interessados, geralmente acontece em três dias da semana ou mais, com uma programação que conta com mesas redondas para importantes debates com palestrantes convidados (especialistas da área, sobretudo pesquisadores locais para a compreensão do contexto local da educação matemática e da pedagogia), além de apresentações de trabalhos, realização de oficinas e minicursos para os participantes, os quais são ministrados por

\footnotetext{
${ }^{2}$ O G-Tercoa é um grupo de estudos e pesquisa que mobiliza alunos da Graduação e Pós-Graduação da Linha de Pesquisa Educação, Currículo e Ensino (LECE) e do eixo Ensino da Matemática, que visa partilhar saberes sobre a Educação Matemática nos diversos níveis de ensino, em uma concepção dialógica sobre formação docente, currículo e práticas pedagógicas que entrelaçam a Matemática e a Pedagogia. CNPq: dgp.cnpq.br/dgp/espelhogrupo/0062485487236515.

${ }^{3}$ Disponível em: https://www.instagram.com/gtercoa/. Acesso em: 20 ago. 2020.

${ }^{4}$ Disponível em: https://www.facebook.com/Gtercoa. Acesso em: 20 ago. 2020.

${ }^{5}$ Disponível em: http://www.youtube.com/c/GTERCOAUFC. Acesso em: 20 ago. 2020.

${ }^{6}$ A certificação sempre acontece segundo critérios estabelecidos pelo evento, mediante o cumprimento de um percentual mínimo de carga horária e de acordo com a participação (como palestrante, apresentador de trabalho, organizador, ministrante de oficina ou minicurso).
} 
pesquisadores do grupo G-Tercoa. Vale ressaltarmos que o referido evento (DIMA) sempre aconteceu de forma presencial; todavia, em virtude da pandemia, em 2020, ele aconteceu virtualmente (o Webinário), a fim de adaptar-se ao novo normal.

\section{O WEBINÁRIO IX DIMA}

No ano de 2020, tivemos uma peculiaridade na realização do IX DIMA, o qual aconteceu sob uma proposta de mesa dialógica on-line, em virtude de uma pandemia mundial ocasionada pela COVID-19 e suas consequências, as quais exigiram medidas de isolamento adotadas pela OMS, como já afirmado anteriormente. Assim, as reuniões para planejamento, organização e preparativos aconteceram em salas virtuais; a abertura de inscrições em formulário on-line; a construção de textos de divulgação, informações sobre o evento, inscrição com trabalho, normas e prazos, foram elaborados e revisados em equipe por meio de grupos virtuais; assim como ensaios com diferentes aplicativos para testes foram realizados, evitando possíveis contratempos. De igual modo, os textos de convite para os palestrantes convidados foram construídos, revisados e enviados fazendo uso das tecnologias e obedecendo às medidas de isolamento social.

O webinário aconteceu entre os dias 4 e 6 de maio do referido ano e trouxe ao público participante uma programação diversificada com mesas on-line, oficinas e minicursos virtuais, prestigiados por um total de 60 participantes (diretamente no momento da transmissão) e outros tantos que assistiram ao evento e participaram por comentários ou outras contribuições relativas às palestras e aos minicursos realizados durante o encontro. As mesas trouxeram temas como: "Plataforma Brasil, entenda como funciona”; "A matemática e o desafio de ensinar a ensinar" ; "Atividades remotas: o professor e as atividades educativas em tempos de pandemia” ${ }^{9}$.

A mesa de encerramento, no dia 6 de maio, Dia Nacional da Matemática, contou com um público de 60 participantes e trouxe a temática "Sequência Fedathi e a EAD" ${ }^{10}$. A interação aconteceu a partir de curtidas e comentários no chat; e, semelhantemente a uma mesa redonda convencional, os participantes poderiam fazer perguntas aos palestrantes. A Sequência Fedathi é uma temática estudada pelo grupo G-Tercoa e constitui-se de uma metodologia que visa contribuir para a formação do professor mediador, "[...] composta por quatro etapas sequenciais e interdependentes, assim denominadas: Tomada de Posição, Maturação, Solução e Prova” (SOUZA, 2013, p. 18).

Os minicursos foram exibidos ao longo de quatro dias e trouxeram temáticas como: "O uso do Kahoot como ferramenta de aprendizagem"11, "Planilhas eletrônicas como ferramenta no ensino de matemática" ${ }^{12}$, "Excel simples" ${ }^{13}$, "Ferramentas da Web" ${ }^{14}$. Todas as ações e aprendizagens vivenciadas justificam-se pelo fato de que as Tecnologias Digitais da Informação e Comunicação (TDIC) transformaram “[...] a maneira como desenvolvemos as atividades em praticamente todos os segmentos da sociedade, bem como o modo como as pessoas pensam, resolvem problemas, acessam a informação e se relacionam socialmente” (VALENTE, 2018, p. 21).

\footnotetext{
${ }^{7}$ Mesa on-line: Plataforma Brasil, entenda como funciona. Disponível em: https://youtu.be/kOO1lA7ICzY. Acesso em: 20 ago. 2020.

${ }^{8}$ Mesa on-line: A matemática e o desafio de ensinar a ensinar. Disponível em: https://www.youtube.com/watch?v=q98yfHZDRpw. Acesso em: 20 ago. 2020.

${ }^{9}$ Mesa on-line: Atividades remotas: o professor e as atividades educativas em tempos de pandemia. Disponível em: https:// www.youtube.com/watch?reload=9\&v=xi1qeipRTu0. Acesso em: 20 ago. 2020.

${ }^{10}$ Mesa on-line: Sequência Fedathi e EAD. Disponível em: https://www.youtube.com/watch?reload=9\&v=neYS305OhkY. Acesso em: 20 ago. 2020.

${ }^{11}$ Minicurso: O uso do Kahoot como ferramenta de aprendizagem. Disponível em: https://youtu.be/3RWaT2nvZFM. Acesso em: 20 ago. 2020.

${ }^{12}$ Minicurso: Planilhas eletrônicas como ferramenta no ensino de Matemática. Disponível em: https://youtu.be/6XijiRhhFRs. Acesso em: 20 ago. 2020.

${ }^{13}$ Minicurso: Excel simples. Disponível em: https://www.youtube.com/watch?v=_NTYPsimhSA. Acesso em: 20 ago. 2020.

${ }^{14}$ Minicurso: Ferramentas da Web. Disponível em: https://www.youtube.com/watch?reload=9\&v=neYS305OhkY. Acesso em: 20 ago. 2020.
} 
A programação completa do IX DIMA on-line apresentada virtualmente consta no canal do G-Tercoa no site do YouTube para posteriores visualizações, comentários, tira-dúvidas, curtidas, entre outras interações por parte dos participantes, cujas impressões destacamos na seção a seguir.

\section{CONSIDERACÕES FINAIS}

A experiência relatada neste ensaio mostra que é possível reunir pessoas para estudar, pesquisar, discutir, ampliar conhecimentos, socializar experiências, mesmo em tempos de isolamento, com atividades presenciais suspensas em virtude de uma pandemia mundial. Utilizamos, para isso, as TDIC, pois “[...] essas tecnologias já fazem parte da nossa vida e já transformaram a maneira como lidamos, por exemplo, com o comércio, os serviços, a produção de bens, o entretenimento e a interação social” (VALENTE, 2018, p. 19), conforme dito anteriormente.

Como pontos positivos a respeito da realização do webinário, destacamos o engajamento, a aprendizagem e a superação do grupo em realizar um evento inteiro em caráter virtual; a interação e a participação do público que tornou possível a realização do IX DIMA on-line. Apontamos, também, a possibilidade de inserir, em um repositório do G-Tercoa, todo o material produzido no evento, tornando-o disponível no canal do YouTube para visualizações posteriores; além do uso das tecnologias, que possibilitou a realização do encontro e o ajuntamento de todos os envolvidos, mesmo em situação de isolamento social, cada um em sua casa, mas empenhados em um mesmo objetivo.

A partir da experiência relatada podemos pensar no posicionamento de alguns setores e cursos de graduação da UFC que, diante do posicionamento da referida instituição, ancorada na Resolução $\mathrm{N}^{\circ}$ 8, de 31 de março de 2020, que trata da continuidade do calendário a partir de atividades remotas (UFC, 2020b), apresenta resistência em enfrentar o desafio que nos foi proposto com o advento da pandemia, preferindo interromper suas atividades acadêmicas de acordo com a Nota do Conselho Departamental da Faculdade de Educação da UFC, de 25 de março de 2020 (UFC, 2020a). É certo que não é tarefa fácil pensar em estratégias para realizar aulas, reuniões, entre outros encontros com a finalidade de estudar, pesquisar e discutir a educação, obedecendo às orientações e às medidas de isolamento da OMS.

Todavia, a Faculdade de Educação da UFC, lugar de onde sai as principais pesquisas e contribuições para a educação e de onde emanam as primeiras ações inovadoras ou implementadoras do processo educativo, não deveria cruzar os braços e cessar suas atividades. É preciso apontarmos que as escolas e os professores em geral estão se reinventando para atender às demandas educativas, garantir minimamente a continuidade das aulas dos seus alunos, dentro das possibilidades de ensino que as ferramentas digitais permitem, e mapear as dificuldades dos alunos para atendê-los.

As TDIC têm se mostrado como importantes ferramentas para a educação e, no contexto da pandemia, têm sido um recurso fundamental para dar continuidade às várias atividades de diversas áreas, entre elas o processo educacional, garantindo a continuidade das aulas e atendendo remotamente ao calendário escolar e/ou acadêmico. Concordamos com Valente (2018, p. 18) quando diz que: "Se as pessoas não estiverem preparadas para lidar com essa complexidade, elas terão muita dificuldade para navegar no mar de informações e de novas situações que estão surgindo”. Nesse sentido, ponderamos que este é o momento oportuno para a Faculdade de Educação da UFC repensar sua postura, enfrentar o desafio e se reinventar, assim como outros profissionais da educação e/ou outras áreas, para retomar minimamente suas atividades acadêmicas, evitando comprometer ainda mais o calendário universitário do ano de 2020 por meio de trabalho remoto e com o uso das tecnologias.

\section{REFERÊNCIAS}

BRASIL. Ministério da Saúde. Sobre a doença. 2020. Disponível em: https://coronavirus.saude.gov.br/ sobre-a-doenca. Acesso em: 30 abr. 2020. 
CEARÁ. Decreto $\mathbf{N}^{\mathbf{0}}$ 33.519, de 19 de março de 2020. Intensifica as medidas para enfrentamento da infecção humana pelo novo coronavírus. Fortaleza: Editoração Casa Civil, [2020]. Disponível em: http://imagens.seplag.ce.gov.br/PDF/ 20200319/do20200319p01.pdf. Acesso em: 30 mar. 2020.

JORNAL NACIONAL. Secretaria de Saúde de SP monitora pessoas que estiveram com infectado por coronavírus. G1, 27 fev. 2020. Disponível em: https://g1.globo.com/jornal-nacional/noticia/2020/02/27/ secretaria-de-saude-de-sp-monitora-pessoas-que-estiveram-com-infectado-por-coronavirus.ghtml. Acesso em: 30 abr. 2020.

SANTOS, M. J. C. dos. Reaprender frações por meio de oficinas pedagógicas: desafio para a formação inicial. 2007. Dissertação (Mestrado em Educação) - Faculdade de Educação, Universidade Federal do Ceará, Fortaleza, 2007.

SOUZA, M. J. A. Sequência Fedathi: apresentação e caracterização. In: SOUSA, F. E. E. de et al. (org.). Sequência Fedathi: uma proposta para o ensino de matemática e ciências. Fortaleza: Edições UFC, 2013. p. 15-47.

TARDIF, M. Saberes docentes e formação profissional. 17. ed. Petrópolis: Vozes, 2014.

UFC. Universidade Federal do Ceará. Nota do Conselho da Faculdade de Educação da UFC à comunidade acadêmica e à sociedade cearense: em defesa da formação de professores com qualidade. Fortaleza: UFC, 2020a. Disponível em: https://faced.ufc.br/nota-do-conselho-departamental-da-faced/. Acesso em: 30 mar. 2020.

UFC. Universidade Federal do Ceará. Provimento N$^{\circ}$ 02/2020, de 16 de março de 2020. Dispõe sobre ações a serem realizadas no âmbito da Universidade Federal do Ceará (UFC), em virtude da pandemia decorrente do Coronavírus (SARS-COV-2/COVID-19). Fortaleza: Conselho Universitário, 2020b. Disponível em: http://www.ufc.br/ images/_files/noticias/2020/200317_provimento_02_consuni_ coronavirus.pdf. Acesso em: 30 mar. 2020.

UFC. Universidade Federal do Ceará. Resolução No 08/2020, de 31 de março de 2020. Dispõe sobre ações a serem realizadas no âmbito da Universidade Federal do Ceará (UFC), em virtude da pandemia decorrente do Coronavírus (SARS-COV-2/COVID-19), a partir do dia $1^{\circ}$ de abril de 2020. Fortaleza: Conselho Universitário, 2020c. Disponível em: http://www.ufc.br/noticias/14537-ufc-prorroga-ate-15de-maio-suspensao-de-atividades-presenciais-administrativas-e-academicas. Acesso em: 27 abr. 2020.

VALENTE, J. A. Inovação nos processos de ensino e de aprendizagem: o papel das tecnologias digitais. In: VALENTE, J. A.; FREIRE, F. M. P.; ARANTES, F. L. (org.). Tecnologia e educação: passado, presente e o que está por vir. Campinas, SP: NIED/UNICAMP, 2018. E-book. Disponível em: https:// www.nied.uni camp.br/wp-content/uploads/2018/11/Livro-NIED-2018-final.pdf. Acesso em: 29 abr. 2020.

WHO. World Health Organization. Considerations in adjusting public health and social measures in the context of COVID-19 of 16 april 2020. WHO, 2020. Disponível em: WHO/2019-nCoV/Adjusting_PH_ measures/2020.1. Acesso em: 30 abr. 2020. 